\section{Produção Escrita no Ensino Fundamental com Base no Tripé Gêneros Textuais, Sequências Textuais Didáticas}

\section{Resumo}

Este artigo tem por objetivo analisar as sequências textuais narrativa e descritiva em produções de alunos do Ensino Fundamental, com o intuito de verificar como essas sequências textuais se configuram nas produções escritas dos alunos. O corpus de análise compõe-se de uma produção escrita de uma aluna do 50 ano do Ensino Fundamental, obtido a partir do desenvolvimento de atividades trabalhadas em uma sequência didática de três aulas. Para apresentação de tal propósito, dividiremos o artigo em duas partes: na primeira apresentaremos os conceitos de gêneros textuais, como os de Marcuschi (2002); sequências narrativas, como os de Adam (2008), Cabral (2013) e Sparano e colaboradores (2012); sequências descritivas, como os de Marquesi (2004) e sequências didáticas, como os de Dolz, Noverraz e Schneuwly (2004), entre outros; e, na segunda, analisaremos a produção escrita que apresenta algumas dificuldades, por parte da aluna estudada, na composição de sequências textuais e aponta para a necessidade de atividades de retextualização como possibilidades de trabalho para a melhoria da prática de produção escrita e meio de complementar as lacunas observadas nas análises do corpus.

Palavras-chave: Gêneros textuais. Sequências textuais. Sequências didáticas. Retextualização.

\section{Abstract}

This article aims to analyze narrative and descriptive textual sequences in elementary school students' productions, in order to verify how these textual sequences are configured in students' written productions. The analysis corpus consists of a written production done by a student of the 5th grade of Elementary School, obtained from the development of activities in a three-class didactic sequence.
Prof. ${ }^{a}$ Me. Aila Figueiredo

Mestre em Linguística pela Universidade Cruzeiro do Sul, especialista em Letras Espanhol pela mesma Universidade e graduada em Secretariado Executivo Bilingue Espanhol pela Universidade São Judas Tadeu. Curso de Extensão Universitária (gramática, cultura e literatura) pela Universidade de Salamanca - Espanha e Cursos de Formação Continuada pelos Institutos Hispânico e Miguel de Cervantes de São Paulo. Atualmente é professora da Universidade Cruzeiro do Sul, com experiência nas áreas Administrativa e Educação a Distância. 
In order to present such purpose, we will divide the article in two parts: at first, we will present the concepts of textual genres, such as Marcuschi's (2002); narrative sequences, as in Adam (2008), Cabral (2013) and Sparano and collaborators (2012); descriptive sequences, as presented by Marquesi (2004) and didactic sequences, such as in Dolz, Noverraz and Schneuwly (2004), among others; and, secondly, we will analyze the written production done by the student, that presents some difficulties in the composition of textual sequences, and points to the need for retextualization activities as work possibilities for the improvement of written production practice as a means of complement the observed writing gaps in corpus analysis.

Keywords: Textual Genres. Textual sequences. Didactic Sequences. Re-textualization.

\section{Introdução}

A produção escrita nos anos iniciais do Ensino Fundamental constitui um marco importante para o sucesso escolar futuro. Acreditamos, assim, que a investigação dos processos envolvidos na produção de textos nessa faixa etária pode apontar possibilidades para o trabalho com produção escrita em geral. O trabalho com textos narrativos é significativamente produtivo, por ser apreciado por crianças na faixa etária do Ensino Fundamental - anos iniciais.

Nesse período, são aplicadas várias atividades com o intuito de desenvolver as habilidades de escrita e de leitura. Vale lembrar que, de acordo com Koch e Elias (2010), escrever não é uma tarefa fácil; é uma atividade que envolve aspectos de natureza variada, como a linguística cognitiva, pragmática, sócio-histórica e cultural, ou seja, é preciso que o aluno faça uso de seu conhecimento prévio, utilize um vocabulário adequado, a forma padrão da linguagem e que respeite as características do gênero a ser produzido. É necessário também que saiba identificar se o texto está coeso e coerente, se há uma sequência nas informações, se mantém uma continuidade, para então construir uma unidade de sentido. Tendo esse conhecimento o aluno poderá fazer uma boa produção textual.

Assim, faz-se necessário um estudo de textos narrativos produzidos por alunos do Ensino Fundamental para detectar as suas dificuldades nesse processo. Considerando que os textos narrativos, para além das categorias prototípicas da narrativa, normalmente apresentam elementos de descrição, este estudo pretende analisar e refletir sobre o processo de escrita, principalmente no que se refere aos elementos da sequência textual narrativa e descritiva.

Convencidos das contribuições do conceito de Sequência Didática postulado por Dolz, Noverraz e Schneuwly (2004), apontaremos, neste trabalho, a importância de se trabalhar em sala de aula com gêneros textuais, sequências textuais a partir de sequências didáticas, com o intuito de encontrar uma forma de amenizar as dificuldades no processo de escrita.

Considerando a importância das sequências narrativas e descritivas para a composição de gêneros narrativos, fazemos o seguinte questionamento: em que medida as redações dos alunos do Ensino Fundamental, anos iniciais, contemplam tais sequências?

Dessa forma, o presente trabalho se compõe das seguintes partes, além desta introdução e da conclusão: Gêneros textuais e sequências textuais: implicações teóricas; Análise da escrita de textos narrativos no Ensino Fundamental: desafios e sugestão de sequência didática para aprimoramento da competência escrita.

\section{Gêneros textuais e sequências textuais: implicações teóricas}

Os gêneros textuais acompanham o dinamismo da língua que está sempre se transformando para atender às necessidades da sociedade. Transformam-se, dando origem a novos gêneros e fazendo com que haja um desuso dos mais antigos. Essa transformação torna-se mais perceptível com o surgimento de 
novas tecnologias que fazem aparecer inéditos gêneros textuais para facilitar e acompanhar as exigências da sociedade. Para Marcuschi (2011, p. 23), os gêneros:

[...] são usados como uma noção propositalmente vaga para referir os textos materializados que encontramos em nossa vida diária e que apresentam características sócio-comunicativas definidas por conteúdo, propriedades funcionais, estilo e composição característica.

O autor deixa claro que os gêneros textuais se multiplicam, buscando sempre atender às variedades de atividades desenvolvidas que estão intimamente ligadas ao nosso cotidiano, encaminhando-se para uma hibridização ou mescla e, consequentemente, não há mais categorias de gêneros puros.

Koch e Elias (2010) afirmam que todas as produções orais ou escritas são gêneros textuais, que se classificam em primários e secundários. Os primários são aprendidos no cotidiano, pois são gêneros mais simples, geralmente situações de interação face a face. Os secundários são mais complexos como, por exemplo, um trabalho científico.

Devido à diversidade de gêneros, a escola precisa priorizar e fazer uma seleção para decidir quais poderão ser trabalhados em sala de aula e que merecem ser estudados mais profundamente, selecionando textos que desenvolvam o poder de crítica e que possam levar o aluno à reflexão sobre o processo de escrita.

Consequentemente, deve-se ter atenção ao escolher o gênero a ser trabalhado nas aulas, é necessário conhecer suas características e funções. Somente a partir desse ponto será possivel elaborar bons planos de aula, já que os gêneros textuais são considerados verdadeiros instrumentos que estabelecem uma relação maior, permitindo a produção e compreensão de texto.

Os textos são compostos por uma ou mais sequências textuais. Essas sequências desen- volvem várias funções em sua composição, uma vez que a unidade textual é complexa e se manifesta por meio de aspectos linguísticos.

As sequências são definidas por Adam (2008) como unidades textuais complexas, compostas de um número limitado de conjuntos de proposições. Segundo Adam (2008, p. 204), uma sequência é uma estrutura,

[...] uma rede relacional hierárquica: uma
grandeza analisável em partes ligadas
entre si e ligadas ao todo que elas consti-
tuem; e uma entidade relativamente au-
tônoma, dotada de uma organização in-
terna que lhe é própria, e, portanto, numa
relação de dependência-independência
com o conjunto mais amplo do qual faz
parte (o texto).

Para Marcuschi (2010), a sequência textual designa uma espécie de construção teórica definida pela natureza linguística de sua composição - aspectos lexicais, sintáticos, tempos verbais, relações lógicas etc. Uma sequência textual é, portanto, um conjunto de elementos que proporcionam ao texto características narrativas, descritivas, argumentativas, injuntivas, explicativas e dialogais. Desse modo, podemos considerar sequências textuais como a forma de o texto se apresentar, visando sempre a uma unidade textual coesa e coerente.

Segundo Cavalcante (2012, p. 62), "[...] todo texto é constituído de sequências textuais, que são consideradas unidades estruturais autônomas e cada sequência constitui uma forma de composição com uma função específica". Essa autora também afirma que um mesmo texto pode apresentar diferentes sequências, caracterizando-o como um texto heterogêneo, uma vez que há distintos propósitos comunicativos que indicam naturalmente à qual sequência o texto se refere.

Como a proposta deste trabalho é enfatizar a presença das sequências narrativa e descritiva nas produções dos alunos, que constituem - corpus de análise, ambas são detalhadas a seguir. 


\section{Sequência textual narrativa}

É por meio da sequência textual narrativa que o autor consegue relatar todo o desenvolvimento de uma história ou fato. Está ligada a uma competência narrativa, correspondente a um esquema narrativo que todos possuímos.

Marquesi e Cabral (2005) afirmam que a narrativa reúne conceitos como intenção, intriga, resolução de problemas e tudo isso inserido em uma sequência temporal em que os fatos são apresentados relacionados entre si. Não podemos esquecer, também, da presença dos personagens e do espaço, elementos importantes e constitutivos da narrativa.

Segundo essas autoras, o aspecto temporal e dramático na sequência narrativa é acentuado, uma vez que a narração está relacionada a ações ou acontecimentos em seu desenvolvimento. Afirmam também que:

[...] a narrativa requer do leitor uma competência do tipo lógico, uma vez que ela atualiza um conjunto de classes complementares, constituído na estrutura profunda por uma sintaxe de percursos previsíveis. (MARQUESI; CABRAL, 2005, p. 53)

Uma vez que a sequência textual narrativa é constituída de uma construção organizada de forma estrutural, com a finalidade de cumprir os propósitos comunicativos, cria um sentido textual fundamentado no surgimento de um conflito e na sua resolução por meio de uma ação.

Para realizar as análises nas sequências textuais narrativas, consideraremos as categorias classificadas por Adam (2008), já que são um marco na conceituação de sequência textual narrativa: sempre há uma situação inicial e uma situação final, existindo, nesse meio, uma fase marcada por momento de perturbação, o que desencadeia o clímax da sequência textual narrativa, com o objetivo de manter a atenção do leitor/ouvinte em relação ao que se conta. Após a resolução do conflito, a sequência textual narrativa seguirá para a situação final, criando um novo estado de equilíbrio. Assim, para maior compreensão, conceituaremos as categorias da sequência textual narrativa.

Na situação inicial, é possível verificar se os alunos introduziram as suas narrativas de forma pertinente, ou seja, situadas no tempo, o que torna fundamental a presença de um elemento de localização temporal.

Essa etapa pode ser realizada de várias formas, porém, a mais conhecida é a que encontramos na literatura infantil: a utilização da expressão era uma vez. Igualmente é possível, no entanto, fazer uma introdução usando expressão adverbial de tempo no início do texto como, por exemplo, um dia, uma vez etc.

Ainda no que se refere à situação inicial, além da introdução, é necessário informar ao leitor onde - o local - em que ocorre a história ou o acontecimento narrado, apresentando o cenário.

Dando continuidade à narrativa, encontramos o conflito ou o nó, como conceitua Adam (2008). Esse é o momento de maior tensão, pois exige também uma solução para o conflito criado, o que, às vezes, requer mudanças nos comportamentos dos personagens ou dos acontecimentos relatados. Esse é o momento em que a história atinge o clímax.

Seguindo as categorias mencionadas, após o conflito acontece a ação, ou seja, para a resolução do conflito, é preciso que alguma ação seja tomada. Esse momento da narrativa requer que os personagens resolvam o nó criado anteriormente, exigindo a ocorrência de novos fatos para transformar a situação e tentar chegar à resolução do problema. Esses fatos colaboram para a reconstrução da narrativa, dando continuidade às sequências que foram desencadeadas pelo problema, com intuito de solucioná-lo. Portanto, é preciso criar uma progressão desses fatos narrados para constituir as ações da sequência textual narrativa e chegar ao fim do conflito.

Quando o conflito já foi resolvido, pode apresentar-se uma nova situação, em que se mostra a transformação em relação ao início da 
narrativa. Chegamos à situação final, momento em que se reestabelece a ordem, criando uma situação estável para a narrativa.

Cumpre destacar que, juntamente com Marquesi e Cabral (2005) e igualmente com Sparano e colaboradores (2012), consideramos como elementos fundamentais na narrativa a existência de um conflito e de uma ação subsequente para resolvê-lo. Com efeito, a narrativa funda-se no agir dos personagens, sem o quê ela não progride. Assim, adotaremos para as nossas análises as seguintes categorias da narrativa: situação inicial, nó ou conflito, ação e situação final.

\section{Sequência textual descritiva}

A sequência textual descritiva encontra-se nos contos, nas novelas, nos trabalhos científicos, na publicidade etc., sendo que, na maioria das vezes, acompanha a sequência textual narrativa, por isso, a descrição ocupa um papel importante, privilegiado, na narração.

Segundo Marquesi (2004), a sequência textual descritiva teve a sua origem com as pesquisas que foram desenvolvidas primeiramente no campo da narrativa e apontaram a importância dos elementos de descrição para o desenvolvimento da narrativa. Isso quer dizer que o ponto de partida dos estudos do descritivo foi a narrativa. De fato, geralmente essas sequências textuais caminham juntas, uma vez que a descrição sempre surge nas narrativas. Segundo essa autora, o descritivo e a narrativa estão lado a lado.

Afirma ainda a autora (MARQUESI, 2004) que o descritivo se caracteriza por uma composição lexical hierarquizada; a descrição dependerá também do conhecimento do autor em termos lexicais, de seu vocabulário. Enfatiza também que a sequência descritiva se caracteriza mais como um processo de colocar em equivalência uma denominação como uma expansão, exigindo do leitor uma competência de saber.

Dessa forma, a descrição dependerá significativamente da competência lexical que tanto produtor quanto leitor tem para descrever, reconhecer e classificar o objeto ou personagem. A sequência textual descritiva tem como traços característicos os tempos verbais no presente do indicativo, nomes próprios, adjetivos e formas adjetivadas do verbo, que reforçam a descrição.

O descritivo desempenha vários papéis dentro do texto narrativo, entre os quais se destacam:

- Construir o cenário da narrativa;

- Fazer o retrato de uma personagem;

- Exprimir o ponto de vista de uma personagem;

- Introduzir enunciados explicativos de ações anteriores;

- Assumir as apreciações e os conhecimentos do autor:

- Anunciar prospectivamente ações mais ou menos previsíveis;

- Estabelecer as isotopias do contexto. (MARQUESI, 2004, p. 71)

Na descrição também encontramos duas características importantes que situam o quadro histórico: a apresentação dos atores ou personagens e do espaço-tempo da narrativa em que ocorre a interação entre os atores.

A autora considera o descritivo uma superestrutura textual que se divide em três categorias: da designação, que corresponde à condensação, da definição e da individuação, as duas últimas correspondendo à expansão. Essas categorias estão nos textos e desempenham uma função que possibilita organizar e classificar diferentes enunciados.

A categoria de designação, como o próprio nome diz, nomeia, qualifica, indica. Segundo a autora, com base em Hamon (1981), trata-se da capacidade que o indivíduo tem de referir-se a algo por uma palavra. Porém, é necessário verificar as relações entre o léxico e o conhecimento de mundo do sujeito, uma vez que cada indivíduo possui experiências que variam de acordo com o contexto social e cultural. 


\section{Análise da escrita de textos narrativos no Ensino Fundamental: desafios e sugestão de sequência didática para aprimoramento da competência escrita - sequência didática}

De acordo com os pesquisadores genebrinos, Dolz, Noverraz e Schneuwly (2004), a fixação é realizada por meio da sequência didática, que constitui um conjunto de atividades escolares organizadas de maneira sistemática, em torno de um gênero textual oral ou escrito, ou seja, são várias atividades planejadas e aplicadas para desenvolver no aluno a capacidade de linguagem que está presente na produção e leitura de textos e podem ser compreendidas como um conjunto de atividades que tem como meta melhorar determinada prática de linguagem. Esses autores afirmam que:

[...] uma sequência didática tem, precisamente, a finalidade de ajudar o aluno a dominar melhor um gênero de texto, permitindo-lhe, assim, escrever ou falar de uma maneira mais adequada numa dada situação de comunicação. (DOLZ; NOVERRAZ; SCHNEUWLY, 2004, p. 97)

Dessa forma, a sequência didática pode ser compreendida como uma unidade de trabalho escolar, uma vez que propõe atividades com objetivos de melhorar determinada prática de linguagem; isto é, segundo os autores, a sequência didática possibilita ao aluno praticar os aspectos de linguagem que estão internalizados, que fazem parte dos seus conhecimentos prévios, mas sobre os quais ainda não tem total domínio.

Tal esquema facilita a aprendizagem, uma vez que utiliza a sequência didática com os gêneros textuais seguindo um processo contínuo, que trabalha dificuldades conforme surgem, respeitando o processo peculiar do grupo.

Quadro 1.

\begin{tabular}{|c|c|c|c|c|c|}
\hline $\begin{array}{c}\text { Apresentação } \\
\text { da situação }\end{array}$ & $\begin{array}{c}\text { Produção } \\
\text { inicial }\end{array}$ & Módulo 1 & Módulo 2 & Módulo N & $\begin{array}{c}\text { Produção } \\
\text { final }\end{array}$ \\
\hline
\end{tabular}

Fonte: adaptado de Dolz, Noverraz e Schneuwly (2004, p. 98).

\section{A sequência didática que deu origem ao corpus de análise}

A seguir, apresentamos as aulas que foram desenvolvidas com alunos do 50 ano do Ensino Fundamental - anos iniciais. As aulas seguem uma sequência didática, iniciando com a introdução de um novo gênero textual, para chegar, afinal, à produção das sequências textuais narrativas e descritivas, que são o foco deste estudo.

\section{Aula I}

A aula I engloba duas etapas do esquema proposto por Dolz, Noverraz e Schneuwly (2004), o que corresponde à apresentação da situação e à produção inicial; portanto, os alunos tiveram o primeiro contato com o gênero estudado neste caso, o conto. Nesse primeiro momento, foram realizadas algumas perguntas de verificação acerca do conhecimento que os estudantes tinham do gênero, ou seja, o trabalho centrou-se na exploração e conscientização dos conhecimentos prévios de cada aluno.

Para dar início às atividades, foi considerada a teoria de Marcuschi (2002, p. 23), em que "[...] os gêneros são usados propositalmente para refletir sobre situações diárias, características definidas por conteúdo, propriedades funcionais, 
estilo e composição". A partir disso, foram instigados com algumas perguntas sobre conto, a saber:

1. Quem lembra de um conto e quer contá-lo?

2. A partir de que idade você começou a ouvir ou ler contos?

3. Você teve alguém que lhe contasse histórias, quando pequeno(a)?

4. Qual é o conto dos que você já ouviu ou leu de que você mais gosta, ou que ficou marcado na sua memória?

5. Qual o personagem de conto de que você mais gosta?

6. O conto é em verso ou em prosa, predominantemente?

7. Quem sabe dizer como se organiza um conto, ou seja, o que é constante nos contos?

8. Quais personagens costumam atuar nos contos de fadas? E quais objetos, mágicos ou não, costumam fazer parte dessas histórias?

Essas perguntas permitem construir uma representação da situação de comunicação. As respostas foram diversificadas, mas houve predominância de A Bela e a Fera nesse grupo. Nos demais, foram citados diferentes contos de fadas ou tradicionais, bem como os seus personagens.

Em um segundo momento, foram lidos aos alunos dois contos acumulativos: $\mathbf{O}$ macaco perdeu a banana e $\mathbf{O}$ menino e a vó gulosa, de Câmara Cascudo.

\section{Aula II}

A aula II dessa sequência corresponde aos módulos I e II do esquema proposto pelos autores citados; intitulava-se "estamos nos conhecendo" e consistiu na realização de uma segunda dinâmica de apresentações seguida da leitura do seguinte parágrafo:

Eu gosto muito mais de Peter Pan do que de outros personagens dos contos de fada porque eu, como ele, não queria crescer, eu não queria sair do tempo da brincadeira. Acho que brincar é tão bom!

Em seguida, os alunos foram convidados a responder à seguinte pergunta, completando a lacuna com o nome do personagem de histórias preferido:

1. Por que você escolheu como seu personagem preferido entre os contos que você já leu, ou já ouviu?

As respostas foram acompanhadas durante a produção e lidas em voz alta pelos estudantes.

Em outra folha foi apresentada aos alunos a descrição de um personagem masculino e um feminino. Depois da leitura, foi pedido que descrevessem o seu personagem preferido receberam a folha e puderam acompanhar a leitura, como se segue:

I Era uma vez uma pequena aldeã, a menina mais bonita que poderia haver. Sua mãe era louca por ela e a avó, mais ainda. Esta boa senhora mandou fazer para a menina um pequeno capuz vermelho. Ele the assentava tão bem que por toda parte aonde ia a chamavam Chapeuzinho Vermelho. (Fonte: Contos de fadas, de Perrault, Grimm, Andersen e outros, p. 77)

II [...] o menino era pequenino e os pais the puseram o nome de Pequeno Polegar. Tudo o que foram capazes de imaginar deram à criança: não queriam que the faltasse nada. Com tudo isso, porém, Pequeno Polegar permanecia exatamente como era no dia do nascimento: não crescia. Seus olhos eram brilhantes, sua inteligência viva e seus gestos ágeis, de modo que tudo o que ele fazia, fazia muito bem feito. (Fonte: Contos de Grimm, Pequeno Polegar, p. 86)

Na sequência, receberam a seguinte instrução:

2. Depois de ler a descrição de um personagem feminino e um masculino de conto de fadas, descreva o seu personagem preferido - que você tem na memória. 
A última atividade dessa aula foi ler o conto de fadas Chapeuzinho Vermelho, de Charles Perrault, publicado na obra Contos de fadas, com apresentação de Ana Maria Machado.

Todas essas atividades constituem-se em elementos fundamentais na elaboração de conteúdos.

\section{Aula III}

A aula III corresponde ao último momento dessa sequência didática e contemplou o módulo III e a produção final, conforme proposto no esquema já citado.

Em seguida, o tex to $O$ retrato de Narizinho foi entregue aos alunos e lido para os quais, a saber:

\section{Retrato de Narizinho.}

Narizinho tem sete anos, é morena como jambo, gosta muito de pipoca e já sabe fazer uns bolinhos de polvilho bem gostosos (Fonte: adaptado de Reinações de Narizinho, de Monteiro Lobato)

\section{Cenário de Dona Benta e de Narizinho.}

Numa casinha branca, lá no sítio do Pica- Pau Amarelo, mora uma velha de mais de sessenta anos. Chama-se Dona Benta. Quem passa pela estrada e a vê na varanda, de cestinha de costura ao colo e óculos de ouro na ponta do nariz, segue seu caminho pensando: - Que tristeza viver assim tão sozinha neste deserto. Mas engana-se. Dona Benta é a mais feliz das vovós, porque vive em companhia da mais encantadora das netas - Lúcia, a menina do narizinho arrebitado, ou Narizinho como todos dizem.

Após a leitura, foi pedido aos alunos que fizessem a produção final que correspondia à produção de um texto contendo as seguintes partes:

1. O retrato escrito de uma pessoa querida;

2. Criar um cenário onde vive essa pessoa;

3. Um dia...: continuar e contar uma história.

Podemos perceber, pelo relato das aulas, que as atividades seguem uma sequência didática que, de acordo com Dolz, Noverraz e Schneuwly (2004, p. 12),
[...] começa pela definição do que é preciso trabalhar a fim de desenvolver as capacidades de linguagem dos alunos que, apropriando-se dos instrumentos de linguagem próprias ao gênero, estarão mais preparados para realizar a produção textual.

Dessa forma, as sequências didáticas apresentadas foram fundamentais para que os alunos realmente produzissem os textos que elaboraram.

\section{Análise do corpus}

O corpus de análise constitui-se de uma produção escrita de uma aluna do $5^{\circ}$ ano do Ensino Fundamental, obtido a partir do desenvolvimento de atividades trabalhadas em uma sequência didática de três aulas. Analisaremos a produção que apresenta algumas dificuldades, por parte da aluna, na composição de sequências textuais e aponta para a necessidade de atividades de retextualização como possibilidades de trabalho para a melhoria da prática de produção escrita e meio de complementar as lacunas observadas nas análises do corpus.

A observação do corpus será composta primeiramente pela apresentação da produção escrita e em seguida das análises das sequências textuais narrativa e descrita.

\section{Produção escrita}

Um dia, em Guarapuava - PR, eu estava com a minha melhor amiga: Isabela!! Ela é uma das melhores amigas, é uma das methores amigas que alguém pode ter! Me entende mais do que minhas outras amigas.

Ela tem o cabelo grande! Como a rapunzel!

É bonita! Tem cabelos pretos, gosta de tudo que eu gosto. É engraçada, divertida, alegre e etc. Tem os olhos pretos. E bem bonitos.

Uma vez, a minha amiga Lilyan tinha vindo na minha casa. E naquele dia, a minha amiga Isabela estava lá.

A gente teve uma briga, só que por sorte tudo acabou bem. Todos nós voltamos a ser amigas de novo. Eu espero que um dia nós 3 voltemos a se ver de novo! 


\section{Sequência textual narrativa}

Quadro 2.

\begin{tabular}{|l|l|}
\hline $\begin{array}{l}\text { Situação inicial } \mathbf{1} \\
\text { Situação inicial } \mathbf{2}\end{array}$ & $\begin{array}{l}\text { "Um dia, em Guarapuava - PR, eu estava com a minha melhor amiga: Isabela!!" } \\
\text { minha amiga Isabela estava lá." }\end{array}$ \\
\hline Nó - conflito & "A gente teve uma briga [...]" \\
\hline Ação & ---- \\
\hline Situação final & "[...] tudo acabou bem. Todos nós voltamos a ser amigas de novo." \\
\hline
\end{tabular}

Fonte: elaborado pela autora.

Percebemos que a aluna já tem o entendimento da narrativa internalizado, em função da utilização, na situação inicial, da expressão adverbial - "Um dia, em Guarapuava - PR [...]" e, no quarto parágrafo, da expressão: "Uma vez, a minha amiga Lilyan [...]". Essas são expressões que caracterizam a narrativa, principalmente porque estão presentes na literatura infantil e indicam a localização temporal, introduzindo a noção de tempo, que remete ao passado, enfatizado pela conjugação do verbo no pretérito imperfeito - "Um dia, em Guarapuava - PR, eu estava com a minha melhor amiga: Isabela!! [...] Uma vez, a minha amiga Lilyan tinha vindo na minha casa. E naquele dia, a minha amiga Isabela estava lá."

Em seguida surge o elemento problematizador, que acaba por desencadear o nó, um conflito, indicando uma complicação da sequência narrativa - "A gente teve uma briga [...]" -, ou seja, até o momento, tudo estava bem. A narradora- personagem só tinha elogios para a sua amiga Isabela, mas, ao direcionar à amiga Lilyan, inicia-se um conflito, pois a forma de apresentá-la é diferente. Parece que ninguém a esperava, que veio sem avisar, simplesmente apareceu no exato momento em que a Isabela estava lá. Outro fato que chama a atenção é que em nenhum momento a amiga Lilyan é elogiada, o que permite inferir que a amizade entre as quais é diferente e que há certo distanciamento.
O conflito chega ao clímax no momento do desentendimento - "A gente teve uma briga [...]". Por que será que brigaram? A amiga Lilyan sentiu ciúmes de Isabela? Os motivos da briga não ficaram claros. Além disso, a aluna não explicita a ação que conduziu a que tudo acabasse bem e as personagens voltassem a ser amigas. Quais foram as atitudes tomadas para que tudo acabasse bem? Percebemos que existe uma lacuna na narrativa, uma vez que a resolução, isto é, a situação final em que tudo acaba bem - "Todos nós voltamos a ser amigas de novo" - ocorre sem que nada seja feito nesse sentido, sem que haja uma ação por parte dos personagens; há apenas o fechamento da história.

Fica claro que a aluna teve uma dificuldade em dar sequência ao texto, pois não apresentou uma ação, criando uma lacuna que interfere em sua compreensão. Portanto, há uma ruptura da narrativa, o que ocasionou uma desarmonia sequencial, tornando o texto incoerente, uma vez que o texto coeso e coerente precisa de uma progressão dos fatos narrados.

Quanto à estrutura da redação, verificou-se que a aluna reconhece que o gênero textual é o de um conto; porém, percebemos que também apresenta algumas dificuldades que deverão ser trabalhadas por meio das atividades de retextualização. 


\section{Sequência textual descritiva}

Fio condutor

Uma das melhores amigas que alguém pode ter

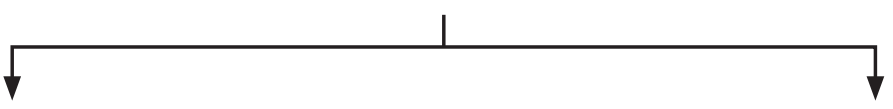

(Condensação)

(Expansão)

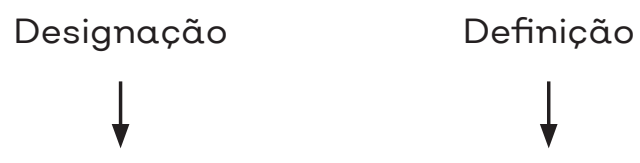

Isabela

Amiga

Figura 1.

Fonte: elaborada pela autora

O fio condutor da aluna é uma das melhores amigas que alguém pode ter; é também responsável pelo ponto de vista que conduz a narrativa. A designação nomeia - Isabela - e a definição categoriza - Amiga. Essa é a forma que a narradora personagem define Isabela. O fio condutor nos leva à expansão, por meio da individuação. As características e aspectos físicos e psicológicos descritos individualizam a personagem, tornando-a única.

A aluna demonstra certa habilidade com a sequência descritiva, quando descreve sua amiga. Percebemos que o conhecimento da descrição já está internalizado, ou seja, mesmo sem ter consciência, a aluna consegue trabalhar os elementos, conforme conceituados na obra de Marquesi (2004).

Como podemos observar na redação, a sequência descritiva é caracterizada pela presença de verbos de estado, como ser, ter etc. - "Ela é uma das melhores amigas [...] ela tem o cabelo grande [...] é bonita! Tem cabelos pretos [...];
É engraçada, divertida, alegre e etc. Tem os olhos pretos [...]". Percebe-se que os verbos estão no presente, uma das características da sequência descritiva.

A aluna também faz uso da classe de palavras mais utilizada na descrição, o adjetivo, para definir os aspectos físicos e as qualidades da amiga Isabela - características (cabelo grande, bonita, engraçada, divertida, alegre, olhos pretos) e qualidades ("Ela é uma das melhores amigas [...]').

Percebemos que é mais fácil para o produtor fazer uso dos elementos descritivos do que usar adequadamente as categorias narrativas, que exigem uma estrutura mais complexa.

Apesar de os elementos descritivos estarem presentes na narrativa, percebemos que há distanciamento entre as sequências textuais analisadas, pois os elementos da descrição não participam dos fatos que compõem a narrativa. 
Embora a aluna contemple elementos ricos relativos à sequência textual descritiva, notamos que a progressão textual fica prejudicada pela falta de uma ação que permita conduzir à situação final, solucionando o conflito apontado. Sugere-se um trabalho de leitura de outras narrativas, destacando a importância da ação para a solução dos conflitos e fechamento da narrativa. Em seguida, pode-se retomar a redação, solicitando à aluna que identifique a ação que encaminha para a resolução. É possivel que reconheça a lacuna, podendo, a partir de um trabalho de reescrita, saná-la.

\section{Considerações finais}

Este estudo pretendeu fazer uma análise das sequências textuais, especificamente, a narrativa e descritiva, tendo como objetivo geral verificar como essas sequências textuais se configuram nas produções escritas dos alunos. A relevância deste estudo concentra-se nas contribuições que a análise pode fornecer para o trabalho com produção textual no Ensino Fundamental, nos anos iniciais.

Para selecionar o corpus de análise, contamos com um período de três aulas que compunham o início de uma sequência didática cujo trabalho centrou-se no gênero conto e desenvolveu atividades de produção textual de pequenos contos, em forma de aulas-oficinas à luz das sequências didáticas de Dolz, Noverraz e Schneuwly (2004).

Elegemos como categorias de análise as das sequências textuais narrativa e descritiva, com base em Adam (2008), Marquesi e Cabral (2005) e Sparano e colaboradores (2012) e em Marquesi (2004), respectivamente. Essa escolha se deu com a finalidade de verificar em que medida os alunos já tinham interiorizado esses componentes, tanto os da sequência narrativa, como os da sequência descritiva.

A análise indica que a aluna possui conhecimento sobre os componentes básicos que caracterizam as sequências textuais narrativa e descritiva. No entanto, fica evidente que apresenta grandes dificuldades quanto à progressão textual, muitas vezes provocada por lacunas em algumas categorias das sequências textuais. Trata-se de um desafio a superar.

Há também problemas de ordem lexical e gramatical, que precisam ser trabalhados em atividades pontuais e transferidos para momentos de retextualização. Podemos afirmar que a análise nos permite avaliar que há muito a se trabalhar relativamente à produção textual.

O estudo como um todo nos permitiu perceber a importância de se trabalhar com gênero textual e sequências didáticas, pois esse conjunto permite aos professores identificarem com mais precisão as diferentes dimensões textuais a serem ensinadas e, como consequência, observar e avaliar melhor as capacidades de linguagem dos alunos, podendo trabalhar com os quais de forma mais eficiente.

Os elementos explorados na análise e o resultado levantado permitem afirmar que os objetivos estabelecidos no início desta pesquisa foram atingidos: identificamos as categorias das sequências textuais narrativa e textual descritiva presentes na produção textual da aluna e, a partir dessa análise, pudemos apresentar reflexões acerca das lacunas relativas à expressão de sequências textuais narrativa e descritiva observadas no corpus analisado e, finalmente, apontar algumas possibilidades de trabalho a ser desenvolvido.

Por fim, cumpre observar que não pretendemos, com este trabalho, esgotar o assunto das sequências textuais narrativa e descritiva, mas apenas refletir acerca de novos caminhos que permitem trilhar no trabalho com produção textual no Ensino Fundamental - anos iniciais -, especialmente tendo o gênero como unidade central de ensino. 


\section{Referências}

ADAM, J. A linguística textual: introdução à análise textual dos discursos. São Paulo: Cortez, 2008.

CABRAL, A. L. T. O conceito de plano de texto: contribuições para o processo de planejamento da produção escrita. Revista Linha D' Água, v. 2, n. 26, p. 241-259, 2013.

CAVALCANTE, M. M. Os sentidos do texto. São Paulo: Contexto, 2012.

DOLZ, J.; NOVERRAZ, M.; SCHNEUWLY, B. Sequências didáticas para o oral e a escrita: apresentação de um procedimento. In: ROJO, R.; CORDEIRO, G. (Org.). Gêneros orais e escritos na escola. Campinas, SP: Mercado de Letras, 2004.

FÁVERO, L. L.; $\mathrm{KOCH}, \mathrm{I}$. V. Linguística textual: introdução. 6. ed. São Paulo: Cortez, 2002.

HUIZINGA, J. Homo Ludens. 6. ed. São Paulo: Perspectiva, 2010.

$\mathrm{KOCH}$, I. V. A coesão textual. 19. ed. São Paulo: Contexto, 2004

;ELIAS, V.M. Ler e escrever: estratégias de produção textual. 2. ed. São Paulo: Contexto, 2010. ;TRAVAGLIA, L. C. A coerência textual. 2. ed. São Paulo: Contexto, 2004.
MARCUSCHI, L. A. Gêneros textuais: configuração, dinamicidade e circulação. In: KARWWOSKI, A. M. et al. (Org.). Gêneros textuais: reflexões e ensino. São Paulo: Parábola, 2011.

Gêneros textuais: definição e funcionalidade. In: DIONÍSIO, A. P. (Org.). Gêneros textuais e ensino. São Paulo: Parábola, 2010.

Gêneros textuais: definição e funcionalidade. In: DIONÍSIO, A. P. (Org.). Gêneros textuais e ensino. Rio de Janeiro: Lucerna, 2002. MARQUESI, S. C. A organização do texto descritivo em língua portuguesa. São Paulo: Lucerna, 2004. .; CABRAL, A. L. T. Enunciação e práticas discursivas na universidade: uma reflexão sobre dificuldades de escrita. In: MICHELETTI, G. (Org.). Enunciação e gêneros discursivos. São Paulo: Cortez, 2008.

Uma proposta de análise dos dados.

São Paulo: Associação Editorial Humanita; Universidade Cruzeiro do Sul, 2005.

SANDIG, B. O texto como conceito prototípico. Rio de Janeiro: Nova Fronteira, 2009.

SPARANO, M. et al. Gêneros textuais: construindo sentidos e planejando a escrita. São Paulo: Terracota, 2012. 